\begin{abstract}
Обоснование. Асептическая нестабильность вертлужного компонента в настоящее время занимает первое место в структуре отдаленных осложнений тотального эндопротезирования тазобедренного сустава. Основу лечения составляет замена расшатанной чашки эндопротеза и пары трения (головка-вкладыш). Тактика действий в отношении же стабильного правильно ориентированного феморального компонента до сих пор не определена, что и подтверждает актуальность исследования. Цель исследования - сравнить эффективность тотальной замены компонентов эндопротеза и изолированной ревизии чашки эндопротеза у пациентов с асептической нестабильностью вертлужного компонента и стабильным правильно ориентированным феморальным компонентом. Методы. Представлены результаты проспективного контролируемого исследования 44 пациентов (45 ревизий) с изолированной асептической нестабильностью вертлужного компонента и стабильным правильно ориентированным феморальным компонентом, которые в зависимости от объема проведенного вмешательства были разделены на две группы. В 1-ю группу были включены 16 пациентов (16 ревизий) с тотальной ревизией компонентов эндопротеза по причине отсутствия головок под нестандартный конус ножки. Во 2-ю группу вошли 28 пациентов (29 ревизий) с изолированной заменой расшатанной чашки эндопротеза и пары трения. Результаты. В 1-й группе, где ревизионное вмешательство помимо замены нестабильной чашки эндопротеза и пары трения включало удаление и замену стабильной правильно ориентированной ножки эндопротеза, были получены более низкие послеоперационные показатели красной крови (эритроциты, гемоглобин, гематокрит), а также более высокие значения оббема интраоперационной кровопотери и продолжительности оперативного вмешательства, чем во 2-й группе, где стабильный правильно ориентированный феморальный компонент сохранялся. Послеоперационные результаты, оцененные при помощи шкал Харриса и Oxford Hip Score, во 2-й группе на всех сроках наблюдения находились на более высоком уровне. Между тяжестью ревизионного вмешательства и его результатами была выявлена корреляционная связь средней силы. Заключение. Сохранение стабильного правильно ориентированного феморального компонента позволяет снизить тяжесть ревизионного вмешательства, что способствует улучшению его результатов и сокращению сроков реабилитации пациентов. Ключевые слова: асептическая нестабильность вертлужного компонента, стабильный правильно ориентированный феморальный компонент, ревизионное эндопротезирование.

(Для цитирования: Марков Д.А., Зверева К.П., Сертакова А.В., Белоногов В.Н., Трошкин А.Ю. Хирургическое лечение изолированной асептической нестабильности вертлужного компонента у пациентов со стабильным феморальным компонентом. Вестник PAMH. 2018;73(3):164-171. doi: 10.15690/vramn974)
\end{abstract}

(C) D.A. Markov, K.P. Zvereva, A.V. Sertakova, V.N. Belonogov, A.Yu. Troshkin Saratov State Medical University named after V.I. Razumovsky, Saratov, Russian Federation

\title{
Surgical Treatment of Isolated Aseptic Acetabular Loosening in Patients with Stable Femoral Component
}

Background: Aseptic acetabular loosening currently occupies the 1st place in the structure of delayed complications after total hip arthroplasty. The basis of treatment is the replacement of a loosening cup and a pair of friction. The tactics of surgical treatment of the stable correctly oriented femoral component have not been determined, thoroughly which confirms the relevance of the study. Aims: Compare the effectiveness of total hip revision and isolated acetabular revision in patients with aseptic acetabular loosening and stable correctly oriented femoral component. Materials and methods: The study presented the results of surgical treatment performed in 44 patients (45 revisions) with isolated aseptic acetabular loosening and stable correctly oriented femoral component were presented, Patients were divided into two groups depending on the severity of surgery. The first group included 16 patients with a total revision due to irregular cone of the stem. The second group included 28 patients (29 revisions) with an isolated replacement of the unstable cup and a pair of friction. Results: In the 1st group, revision surgery was performed to replace both cup with the friction pair and stable correctly oriented stem which finally results in lower postoperative red blood counts (erythrocytes, hemoglobin, hematocrit), as well as higher intraoperative blood loss volume and longer duration of surgical intervention if compare to the 2nd group where the stable correctly oriented femoral component was not changed. Postoperative results assessed using Harris scales and Oxford Hip Score in the comparison group were at a higher level during the whole period of follow-up. A moderate coorelation between the severity of the revision intervention and its results was detected. Conclusions: Preservation of a stable correctly oriented stem allows to reduce the severity of the revision intervention which improves the results and shortens the period of patient rehabilitation.

Key words: aseptic acetabular loosening; stable femoral component; revision arthroplasty.

(For citation: Markov DA, Zvereva KP, Sertakova AV, Belonogov VN, Troshkin AYu. Surgical Treatment of Isolated Aseptic Acetabular Loosening in Patients with Stable Femoral Component. Annals of the Russian Academy of Medical Sciences. 2018;73(3):164-171. doi: 10.15690/vramn974) 


\section{Обоснование}

Асептическая нестабильность вертлужного компонента в настоящее время занимает первое место в структуре отдаленных осложнений тотального эндопротезирования тазобедренного сустава, достигая $40 \%$ в течение 10 лет после первичной установки [1-3]. Современный принцип лечения заключается в проведении ревизионной артропластики с заменой нестабильной чашки эндопротеза и пары трения головка-вкладыш. Хирургическая тактика в отношении стабильного правильно ориентированного феморального компонента в данной ситуации до сих пор не определена. Часть авторов придерживается позиции сохранения стабильной правильно ориентированной ножки эндопротеза для снижения тяжести ревизионного вмешательства $[4,5]$. Другие же, настаивая на невозможности изолированного течения перипротезного ацетабулярного остеолизиса, а также возникающих технических сложностях в обеспечении адекватной визуализации вертлужной впадины выстоящей шейкой эндопротеза, говорят об обязательной замене стабильной ножки [6]. Отсутствие единого подхода в отношении феморального компонента при изолированной асептической нестабильности чашки эндопротеза обусловило актуальность данного исследования.

Цель исследования - сравнить эффективность тотальной замены компонентов эндопротеза и изолированной ревизии чашки эндопротеза у пациентов с асептической нестабильностью вертлужного компонента и стабильным правильно ориентированным феморальным компонентом.

\section{Методы}

\section{Дизайн исследования}

Проведено проспективное нерандомизированное контролируемое исследование, включавшее пациентов с изолированной асептической нестабильностью ацетабулярного компонента и стабильным правильно ориентированным феморальным компонентом, стратификация которых по группам осуществлялась на основании примененного метода ревизионного вмешательства (тотальное ревизионное вмешательство или изолированная замена чашки эндопротеза и пары трения). Обследование больных осуществлялось на 10-е послеоперационные сутки по выписке из стационара, через 3, 6 и 12 мес при помощи клинического, рентгенологического методов исследования и анкетирования по шкале Харриса (Harris Hip Score, HHS) и Оксфордской шкале для тазобедренного сустава (Oxford Hip Score, OHS).

\section{Критерии соответствия}

Для формирования однородных групп были определены критерия включения, невключения и исключения. Критерии включения:

1) изолированная нестабильность вертлужного компонента эндопротеза;

2) наличие стабильного правильно ориентированного феморального компонента;

3) асептический генез патологии;

4) односторонняя асептическая нестабильность вертлужного компонента;

5) дооперационные показатели содержания эритроцитов (red blood cells, RBC), гемоглобина (hemoglobin, HGB), гематокрита (hematocrit, НСТ) в пределах диапазо- на нормы (RBC 4,30-5,80×1012/л; HGB 131-167 г/л; НСТ 0,399-0,510 л/л);

6) сопутствующая патология в стадии компенсации.

\section{Критерии невключения:}

1) тотальная нестабильность компонентов эндопротеза;

2) наличие перипротезной гнойной инфекции;

3) двустороннее поражение тазобедренного сустава;

4) анемия различного генеза различной степени тяжести;

5) сопутствующая патология в стадии декомпенсации.

\section{Критерии исключения:}

1) патология седалищного нерва;

2) выраженная патология коленных и голеностопных суставов;

3) наличие остеопороза по данным лучевых методов исследования.

\section{Условия проведения}

Исследование проведено на базе травматолого-ортопедического отделения № 4 НИИ травматологии, ортопедии и нейрохирургии ФГБОУ ВО «Саратовский государственный медицинский университет имени В.И. Разумовского» Минздрава России.

\section{Продолжительность исследования}

Период включения пациентов в исследование с 1 января 2014 г. по 31 декабря 2016 г. Промежуточные контрольные точки - 10-е послеоперационные сутки, 3 , 6 и 12-й месяцы после операции. Средний срок наблюдения $-22 \pm 7$ мес.

\section{Описание медицинского вмешательства}

Предоперационная подготовка к ревизионному вмешательству осуществлялась согласно протоколу «Эндопротезирование тазобедренного сустава» (год принятия 2013) и включала назначение профилактической антибактериальной терапии цефалоспоринами 3-го поколения (цефтриаксон однократно в дозе 2,0 г внутривенно за 30 мин до операции), очистительной клизмы и антикоагулянтной терапии низкомолекулярным гепарином (Клексан в дозе 0,4 мл подкожно однократно накануне операции).

Оперативное вмешательство у всех 44 пациентов (45 ревизий) осушествлялось под комбинированной анестезией, с искусственной вентиляцией легких, переднебоковым доступом Moore.

Пациентам 1-й группы выполнялось тотальное ревизионное вмешательство с удалением стабильного правильно ориентированного феморального компонента. После вскрытия капсулы и вывихивания головки производилась обработка проксимального отдела бедренной кости специальным набором длинных тонких долот на границе ножка-кость или цемент-кость. Головку удаляли. Экстракцию стабильного правильно ориентированного феморального компонента осуществляли путем установки на нестандартный конус шейки специального инструмента для удаления ножки эндопротеза. Эвакуацию цементной мантии из костномозгового канала при условии цементного типа фиксации выполняли путем ее фрагментации при помощи долот. Производили расстановку 4 ретракторов Хомана по окружности ацетабулярного компонента. Удаление чашки эндопротеза выполняли специальным инструментом. Производили обработку вертлужной впадины риммерами до кровоточащей кости и установку ревизионного ацетабулярного компонента со вкладышем. Рашпилями формировали костномозговой 
канал бедренной кости и осуществляли имплантацию ревизионного феморального компонента. На примерочной головке проверяли сустав на стабильность, после чего производили установку металлической головки и вправление. Рану обильно промывали антисептическим раствором. Производили установку отточной дренажной системы и послойное ушивание.

Пациентам 2-й группы выполнялась изолированная замена расшатанной чашки эндопротеза и пары трения головка-вкладыш. После вскрытия капсулы сустава и вывихивания бедренная кость с имплантированным феморальным компонентом отводилась за задний край вертлужной впадины при помощи ретрактора Хомана. Расстановкой еще 3 ретракторов по окружности чашки эндопротеза обеспечивалась ее адекватная визуализация. Производили удаление расшатанного ацетабулярного компонента. Осуществляли обработку вертлужной впадины риммерами до кровоточащей кости и установку ревизионной чашки со вкладышем. Производили замену установочной головки, после чего выполняли вправление. Рану обильно промывали антисептическим раствором. Производили установку отточной дренажной системы и послойное ушивание.

В раннем послеоперационном периоде всем пациентам продолжалась рациональная антибиотикопрофилактика цефалоспоринами 3-го поколения (цефтриаксон по 1,0 мл 2 раза/сут в течение 5 дней), борьба с тромбообразованием (низкомолекулярный гепарин Клексан по 0,4 мл подкожно, эластическое бинтование нижних конечностей) и анальгетическая терапия (морфин по 1,0 мл внутримышечно в первые послеоперационные сутки при выраженном болевом синдроме, не купируемом приемом нестероидных противовоспалительных средств, а затем Кеторол по 60 мг/сут). Проводилась разъяснительная беседа с больными по поводу ограничения наружной ротации и сгибания в оперированном тазобедренном суставе более $90^{\circ}$. В первые послеоперационные сутки осуществляли активизацию пациентов путем присаживания и назначения дыхательной гимнастики. Со вторых послеоперационных суток обучали ходьбе с дозированной нагрузкой на оперированную конечность при помощи дополнительной опоры на костыли (не более $50 \%$ нагрузки в течение 2 мес), после чего больные переходили на использование трости (1 мес). Об отказе от дополнительной опоры говорили при отсутствии болевого синдрома и признаков остеолизиса по данным контрольных рентгенограмм.

\section{Исходы исследования}

\section{Основной исход исследования:}

- изменение клинического и функционального состояния оперированного тазобедренного сустава;

- отсутствие развития повторной асептической нестабильности ацетабулярного компонента;

- отсутствие развития асептической нестабильности феморального компонента;

- снижение тяжести ревизионного вмешательства при сохранении стабильного правильно ориентированного феморального компонента в виде сокращения продолжительности операции, объема интраоперационной кровопотери и получения послеоперационных показателей красной крови (эритроциты, гемоглобин, гематокрит) на более высоком уровне.

\section{Анализ в подгруппах}

Обследованию и хирургическому лечению были подвергнуты 44 пациента (45 ревизий) с асептической неста- бильностью ацетабулярного компонента и стабильным правильно ориентированным феморальным компонентом. Костные дефекты вертлужной впадины у всех больных соответствовали I-IIB типам по классификации Paprosky. У одного больного оперативное вмешательство производилось с двух сторон в связи с развитием изолированной асептической нестабильности вертлужного компонента в контрлатеральном тазобедренном суставе через 1 год после первого ревизионного эндопротезирования. Все пациенты были разделены на две сравниваемые группы в зависимости от примененного метода лечения:

- в 1-ю группу были включены 16 больных, которым производилось тотальное ревизионное вмешательство с удалением стабильного правильно ориентированного феморального компонента в связи с наличием нестандартного размера конуса и отсутствием под него головок;

- во 2-ю группу исследования были включены 28 пациентов (29 ревизий), которым осуществлялась изолированная замена нестабильной чашки эндопротеза и пары трения; стабильная правильно ориентированная ножка эндопротеза сохранялась.

\section{Методы регистрации исходов}

Определение тяжести ревизионного вмешательства осуществляли на основании оценки продолжительности операции, объема интраоперационной кровопотери и показателей красной крови (RBC, HGB, НCT) на 10-е послеоперационные сутки (анализатор гематологический автоматический МЕК модель 8222 K (Nihon kohden corporation, Япония; регистрационное удостоверение № РЗН 2014/2131).

Комплексная оценка состояния оперированного тазобедренного сустава включала проведение клинического и рентгенологического исследований. При клиническом обследовании пациентов обращали внимание на состояние послеоперационной раны (отсутствие признаков воспаления), объем движений в оперированном суставе, определяемый при помощи угломера, и разницу длин нижних конечностей при сравнительном измерении анатомической и функциональных длин. Рентгенологическое исследование производилось в 2 стандартных проекциях (переднезадней и аксиальной) с выявлением критериев асептической нестабильности Н.В. Загороднего (2011) по зонам DeLee-Charnley и Gruen для ацетабулярного и феморального компонентов соответственно.

Результаты хирургического лечения оценивались при помощи стандартных анкет-опросников (HHS, OHS).

Градация по шкале HHS:

- отличный результат - 90-100 баллов;

- хороший результат - 80-89 баллов;

- удовлетворительный результат - 70-79 баллов;

- неудовлетворительный результат - 69 баллов и менее. Градация по шкале OHS:

- имеется тяжелая патология тазобедренного сустава, требующая хирургического лечения, - 0-19 баллов;

- имеется патология тазобедренного сустава, требующая дополнительного обследования и выполнения рентгенологического исследования с возможным проведением оперативного вмешательства, - 20-29 баллов;

- имеется патология тазобедренного сустава, требующая консервативного лечения (лечебная физкультура, снижение веса и прием нестероидных противовоспалительных средств), - 30-39 баллов;

- удовлетворительное состояние тазобедренного сустава, не требующее лечения, - 40-49 баллов. 


\section{Этическая экспертиза}

Исследование проводилось на основании подписания информированного согласия пациентами и разрешения Локального этического комитета при ФГБОУ ВО «СГМУ им. В.И. Разумовского» Минздрава России (протокол № 6 от 14.03.2014) в соответствии с этическими стандартами, разработанными в соответствии с Хельсинской декларацией Всемирной ассоциации «Этические принципы проведения научных медицинских исследований с участием человека» с поправками 2000 г. и Правилами клинической практики в Российской Федерации, утвержденными Приказом Минздрава РФ от 19.06.2003 г. № 266.

\section{Статистический анализ}

\section{Принципы расчета размера выборки}

Размер выборки предварительно не рассчитывался и определялся имеющимся количеством больных, соответствующим установленным критериям включения, невключения и исключения.

\section{Методы статистического анализа данных}

Статистическая обработка данных производилась при помощи пакета надстроек к Microsoft Excel AtteStat 12.0.5 (Microsoft Corporation, США). Количественные показатели представляли в формате медианы (Ме) и интерквартильного размаха $\left[\mathrm{Q}_{1} ; \mathrm{Q}_{3}\right]$. Оценку значимости различий медиан осуществляли при помощи непараметрического критерия Манна-Уитни в связи с малочисленностью выборок и опровержением гипотезы о нормальном распределении вариационных рядов критериями ШапироУилка, Смирнова, Колмогорова. Наличие связи между признаками выявляли с помощью корреляционного анализа с построением корреляционной матрицы и вычислением коэффициента корреляции Пирсона. Статистическая гипотеза считалась достоверной при $p<0,05$.

\section{Результаты}

\section{Объекты (участники) исследования}

В исследовании приняли участие 44 пациента с изолированной асептической нестабильностью ацетабулярного компонента и стабильным правильно ориентированным феморальным компонентом. Соотношение женщин и мужчин в исследовании составило 2:1 (29 женщин и 15 мужчин). Средний возраст больных $58,2 \pm 10,56$ года. Стратификация больных по возрасту и полу представлена в табл. 1.

Сопутствующая патология по данным обследований, представленным при госпитализации, была зарегистрирована у 33 (75\%) пациентов: преобладали поражения сердечно-сосудистой, эндокринной и дыхательной систем.

\section{Основные результаты исследования}

Сравнение тяжести ревизионного вмешательства в исследуемых группах осуществляли путем оценки про- должительности операции, объема интраоперационной кровопотери и послеоперационных показателей красного ростка крови (RBC, HGB, HCT) на 10-е сутки.

Оценка продолжительности операции в группах исследования показала статистически достоверное увеличение затрачиваемого времени практически в 2 раза при проведении тотального вмешательства с удалением стабильного правильно ориентированного феморального компонента (продолжительность операции в 1-й группе - 132,5 [115; 150] мин, во 2-й - 80 [67,5; 90] мин; $\left.p=2,67 \times 10^{-7}, p<0,05\right)$. Средние значения объема интраоперационной кровопотери в 1-й группе исследования статистически достоверно превышали результаты 2-й группы в 3 раза - $900[750 ; 1450]$ и 300 [225; 550] мл соответственно $\left(p=1,04 \times 10^{-6}, p<0,05\right)$. Послеоперационные показатели красной крови, такие как содержание эритроцитов, гемоглобин и гематокрит, оцененные на 10-е сутки, в группе с сохранением стабильного правильно ориентированного феморального компонента находились на более высоком уровне, чем в группе с тотальной заменой компонентов. Так, содержание эритроцитов у пациентов 1-й группы фиксировалось на уровне $3,26 \times 10^{12} /$ л $[2,985$; $3,52]$, во 2 -й $-3,97 \times 10^{12} /$ л $[3,825 ; 4,13]\left(p=1,169 \times 10^{-6}\right.$, $p<0,05)$. Значения гемоглобина у пациентов 2-й группы (112 [108; 118] г/л) также статистически достоверно превышали полученные данные у пациентов 1-й группы (90 $[87,5 ; 97]$ г/л; $\left.p=5,931 \times 10^{-6}, p<0,05\right)$. Подобные результаты были отмечены и при сравнении средних значений гематокрита $-0,375$ л/л [0,346; 0,383] в группе с сохраненной ножкой эндопротеза и 0,286 л/л [2,265; 0,304] в группе с тотальной ревизией $\left(p=3,434 \times 10^{-7}, p<0,05\right)$.

Функциональный результат лечения на 10 -е послеоперационные сутки, через 3, 6 и 12 месяцев при помощи анкет-опросников OHS и HHS был оценен у всех 44 пациентов (45 ревизий).

Результаты хирургического лечения по шкале Харриса у пациентов 2-й группы исследования на всех сроках наблюдения статистически достоверно регистрировались на более высоком уровне, чем в 1-й группе. Результаты лечения по шкале Харриса представлены на рис. 1.

Удовлетворительный функциональный результат лечения, достаточный для нормальной жизнедеятельности пациентов, в группе с тотальной ревизией компонентов эндопротеза достигался в течение 6 мес, в группе с изолированной заменой нестабильной чашки эндопротеза и пары трения - в течение 3 мес, что говорило о сокращении сроков реабилитации пациентов при сохранении стабильного правильно ориентированного феморального компонента.

Окончательный результат хирургического лечения по шкале Харриса, оцениваемый через 12 мес после ревизионного вмешательства, в 1-й группе регистрировался на уровне «удовлетворительный», во 2-й - на уровне «хороший».

Согласно шкале OHS также были показаны более низкие значения результатов хирургического лечения в 1-й группе исследования на всех сроках реабилитации,

Таблица 1. Характеристика пациентов по половому и возрастному критерию

\begin{tabular}{|c|c|c|c|c|c|c|c|}
\hline \multirow{2}{*}{ Участники } & \multicolumn{6}{|c|}{ Возраст, лет } & \multirow{2}{*}{ Всего } \\
\hline & $20-30$ & $31-40$ & $41-50$ & $51-60$ & $61-70$ & $71-80$ & \\
\hline Женщины, $n$ (\%) & 0 & $4(9,1)$ & $4(9,1)$ & $9(20,5)$ & $7(15,9)$ & $5(11,4)$ & $29(65,9)$ \\
\hline Мужчины, $n$ (\%) & $1(2,3)$ & 0 & $2(4,55)$ & $3(6,82)$ & $6(13,64)$ & $3(6,82)$ & $15(34,1)$ \\
\hline Всего, $n(\%)$ & $1(2,3)$ & $4(9,1)$ & $6(13,6)$ & $12(27,3)$ & $13(29,5)$ & $8(18,2)$ & $44(100)$ \\
\hline
\end{tabular}




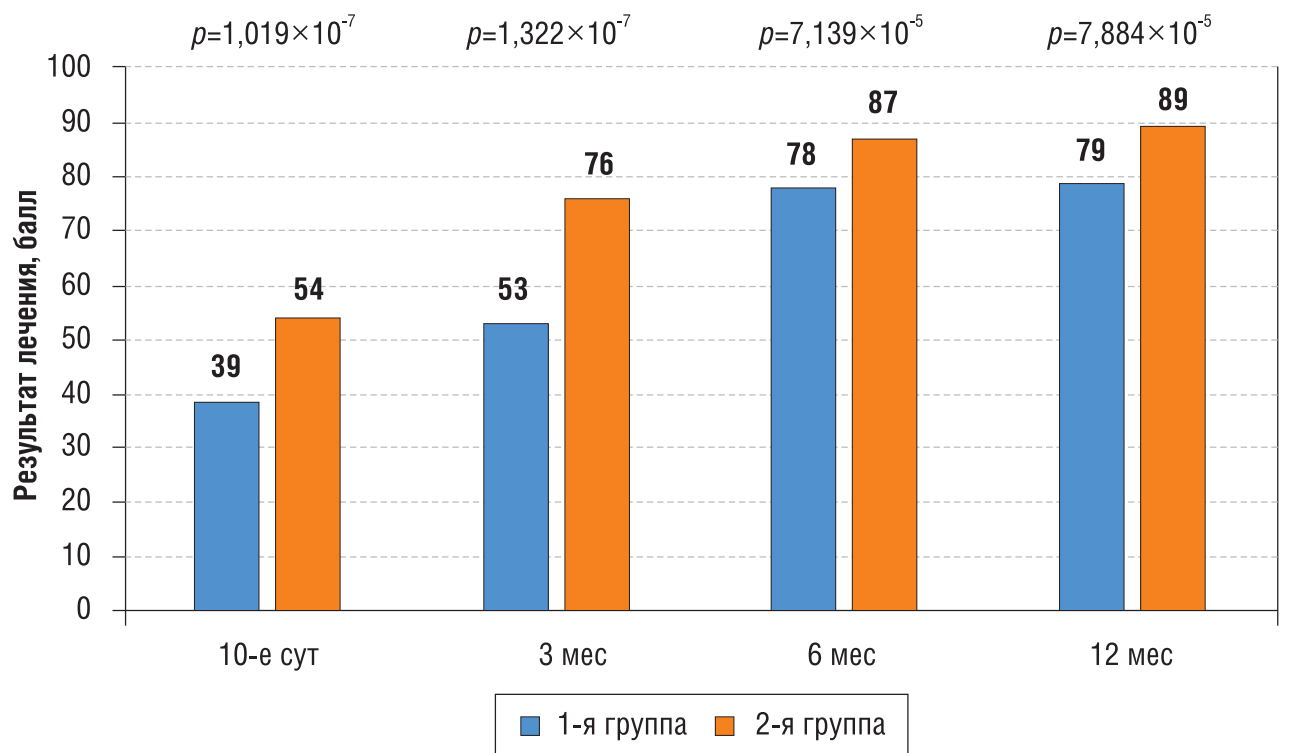

Рис. 1. Результаты лечения по шкале Харриса

Примечание. $p$ - фактически достигнутый уровень значимости критерия Манна-Уитни.

чем во 2-й. Окончательный результат хирургического лечения, оцененный через 1 год после ревизионного вмешательства, в группе с сохраненным феморальным компонентом находился в промежутке от 40 до 48 баллов, что говорило о полноценном восстановлении оперированного сустава. В группе с проведенной тотальной ревизией окончательный результат хирургического лечения был получен на уровне от 30 до 39 баллов, что указывало на необходимость проведения дополнительных реабилитационных мероприятий для полноценного восстановления тазобедренного сустава. Результаты хирургического лечения в 1-й и 2-й группах исследования по шкале OHS представлены на рис. 2.

Изучение связи между показателями тяжести ревизионного вмешательства и результатами хирургического лечения осуществляли с помощью корреляционного анализа с построением корреляционной матрицы и определения коэффициента Пирсона. Корреляционная матрица представлена в табл. 2.
Корреляционная связь средней силы была выявлена между всеми показателями тяжести ревизионного вмешательства и результатами лечения. Так, между показателями красной крови (RBC, HGB, HCT) и результатами лечения была выявлена положительная корреляционная связь средней силы, что говорило об улучшении послеоперационных результатов лечения при увеличении показателей красной крови. Между объемом интраоперационной кровопотери и результатами лечения была получена отрицательная корреляционная связь средней силы, что указывает на ухудшение результатов лечения при увеличении объема кровопотери. Подобный результат с получением отрицательной корреляционной связи средней силы также был выявлен между продолжительностью ревизионного вмешательства и его результатами.

Выживаемость сохраненного феморального компонента для показателя развития асептической нестабильности у пациентов 2-й группы исследования составила $100 \%$.

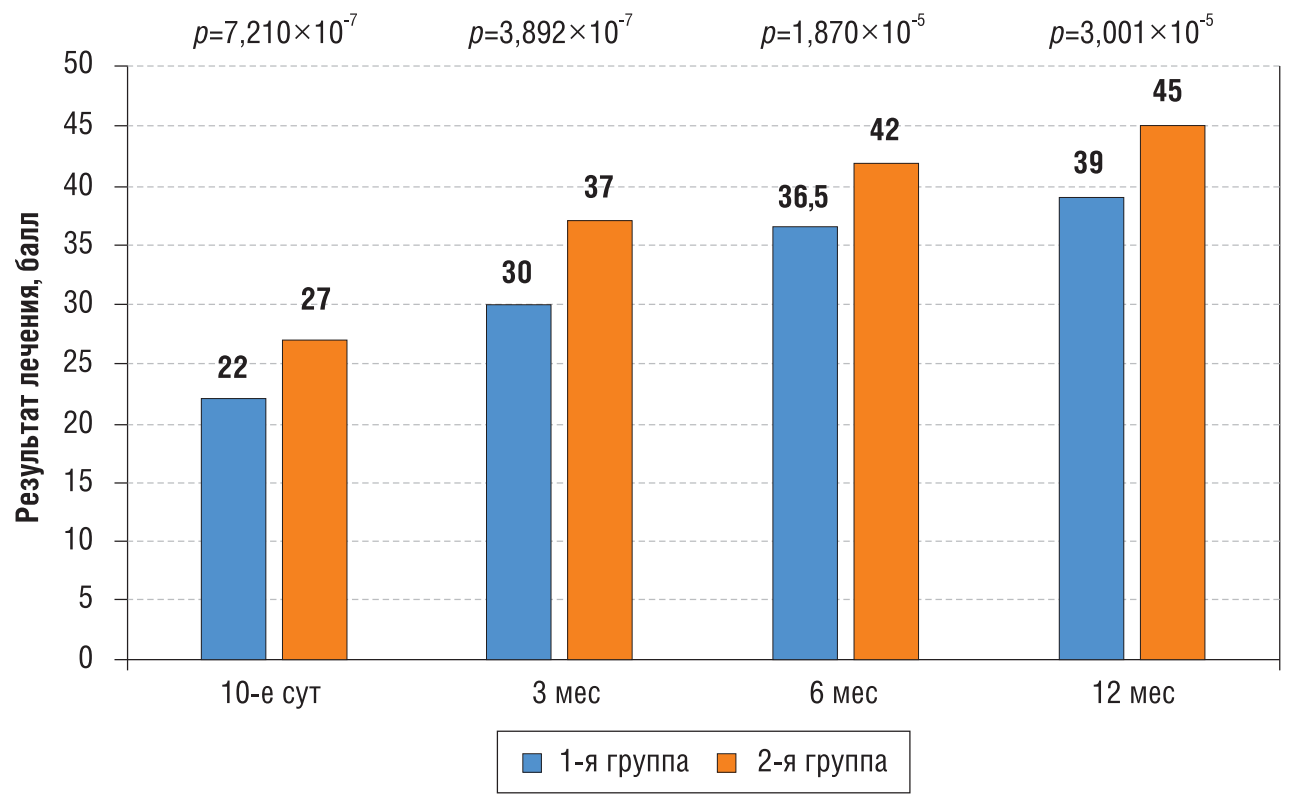

Pис. 2. Результаты хирургического лечения в группах сравнения по шкале OHS

Примечание. $p$ - фактически достигнутый уровень значимости критерия Манна-Уитни. 
Таблица 2. Корреляционная матрица

\begin{tabular}{|c|c|c|c|c|c|c|}
\hline Показатель & RBC & HGB & HCT & $\begin{array}{c}\text { Объем } \\
\text { кровопотери }\end{array}$ & $\begin{array}{c}\text { Продолжительность } \\
\text { вмешательства }\end{array}$ & $\begin{array}{c}\text { Результат } \\
\text { лечения }\end{array}$ \\
\hline $\mathrm{RBC}$ & 1 & 0,848 & 0,849 & $-0,787$ & $-0,794$ & $0,401 *$ \\
\hline HGB & 0,848 & 1 & 0,891 & $-0,804$ & $-0,813$ & $0,514^{*}$ \\
\hline $\mathrm{HCT}$ & 0,849 & 0,891 & 1 & $-0,809$ & $-0,809$ & $0,414^{*}$ \\
\hline Объем кровопотери & $-0,787$ & $-0,804$ & $-0,809$ & 1 & 0,789 & $-0,405^{* *}$ \\
\hline $\begin{array}{l}\text { Продолжительность } \\
\text { вмешательства }\end{array}$ & $-0,794$ & $-0,813$ & $-0,809$ & 0,789 & 1 & $-0,503^{* *}$ \\
\hline Результат лечения & 0,401 & 0,514 & 0,414 & $-0,405$ & $-0,503$ & 1 \\
\hline
\end{tabular}

Примечание. * — положительная корреляционная связь средней силы; ** - отрицательная корреляционная связь средней силы.

\section{Нежелательные явления}

Во 2-й группе через 1 год после первичной ревизии у $2 / 28(7,1 \%)$ пациентов потребовалось проведение реревизии. У одного больного отмечалось развитие повторной асептической нестабильности вертлужного компонента, что, вероятнее всего, связано с падением в раннем послеоперационном периоде. У второго пациента было зарегистировано глубокое параимплантарное нагноение, этиологическими факторами которого могут являться перенесенный гематогенный остеомиелит и оперативные вмешательства на тазобедренном суставе в детском возрасте.

\section{Обсуждение}

\section{Резюме основного результата исследования}

Оптимальным методом хирургического лечения пациентов с асептической нестабильностью чашки эндопротеза является изолированная замена расшатанного вертлужного компонента, характеризующаяся получением высоких послеоперационных результатов и сокращением сроков реабилитации пациентов в 2 раза. Сохранение же стабильного правильно ориентированного феморального компонента при данном методе позволяет сократить продолжительность ревизионного вмешательства на $40 \%$, снизить объем интраоперационной кровопотери на $60 \%$ и улучшить лабораторные показатели (RBC, HGB, HCT) на 20\%. Методами корреляционного анализа выявлена связь средней силы между результатами ревизии и ее тяжестью.

\section{Обсуждение основного результата исследования}

Наиболее эффективным хирургическим методом лечения пациентов с асептической нестабильностью вертлужного компонента являлась изолированная замена чашки эндопротеза и пары трения с сохранением стабильного правильно ориентированного феморального компонента, что подтверждалось получением более высоких значений по функциональным оценочным шкалам HHS, OHS на всех сроках наблюдения и сокращением затраченного времени на реабилитацию. Это объяснялось тем, что оставление ножки эндопротеза позволяет значительно снизить тяжесть ревизионного вмешательства в виде сокращения времени операции и объема интраоперационной кровопотери, а послеоперационные показатели красной крови сохранить на достаточно высоком уровне. В исследовании K. Fukui также было показано, что удаление стабильного феморального компонента увеличивает продолжительность операции, объем интраоперационной кровопотери и приводит к потере костного массива бедренной кости с необходимостью установки компонента бо́льшего размера и проведения ауто- или аллопластики [7].

С помощью методов корреляционного анализа было выявлено наличие связи между тяжестью ревизионного вмешательства и его результатами. Так, с увеличением тяжести ревизионного вмешательства отмечается ухудшение результатов лечения, и наоборот. Наличие корреляционной связи средней силы, вероятно, связано со снижением восстановительных способностей организма в пожилом возрасте на фоне сопутствующей патологии, что подтверждалось наличием коморбидного фона у 75\% обследованных, а абсолютное большинство в исследовании составили больные старше 50 лет. Полученная нами стратификация по возрасту больных согласуется с ежегодными отчетами национальных регистров, где указывается, что основным контингентом при асептической нестабильности вертлужного компонента являются пациенты в возрасте старше 50 лет, причем наличие одной или нескольких сопутствующих патологий регистрируется у каждого второго [8, 9]. В связи с вышеизложенным, рекомендацию о необходимости снижения тяжести операции считаем крайне важной при лечении изолированной асептической нестабильности ацетабулярного компонента.

Основными причинами, ограничивающими сохранение феморального компонента, многие авторы указывают невозможность изолированного течения асептической нестабильности и тотально протекающий процесс ремоделирования костной ткани. Частицы износа пары трения, попав в синовиальную жидкость, запускают каскад воспалительной реакции с активацией остеокластов и возникновением перипротезного остеолизиса вокруг обоих компонентов эндопротеза с их постепенным расшатыванием [10, 11]. Согласно биомеханическим исследованиям, во время работы эндопротеза наибольшая концентрация напряженно-деформирующих сил скапливается в области ацетабулярного компонента, что при начавшемся процессе ремоделирования костной ткани приводит к быстрому развитию клинически значимой нестабильности чашки. Расшатывание же феморального компонента в силу его меньшей нагруженности возникает значительно позже [12]. Частота ревизий на сохраняемой ножке эндопротеза (сроки наблюдений 10-12 лет), по данным зарубежной литературы, колеблется в пределах $3-6 \%$, что сопоставимо с частотой ревизий на заменяемом феморальном компоненте при тотальном вмешательстве [13, 14]. Сопоставимость частоты ревизий на сохраненной и замененной ножке эндопротеза, вероятнее всего, связана с возникающими костными дефектами и необходимостью их пластики при удалении стабильно- 
го компонента, снижающей стабильность конструкции. В нашем исследовании случаев развития асептической нестабильности сохраненной ножки эндопротеза (срок наблюдения $22 \pm 7$ мес) не выявлено. Учитывая сопоставимость выживаемости феморального компонента в случае его замены или оставления, считаем возможным сохранение стабильной правильно ориентированной ножки при клинически определяемом изолированном расшатывании чашки эндопротеза.

Техническая сложность в обеспечении адекватной визуализации вертлужной впадины выстоящей шейкой эндопротеза при условии сохранения стабильного феморального компонента рядом авторов также указывается как причина необходимости выполнения тотального ревизионного вмешательства. Решение проблемы нами видится в правильном выборе хирургического доступа к тазобедренному суставу. Адекватная визуализация вертлужной впадины при сохранении феморального компонента обеспечивается значительным смещением выстоящей шейки эндопротеза кзади, что возможно лишь при использовании комбинированных подходов $[15,16]$. Сохранение отводящего механизма бедра при заднебоковом доступе ограничивает мобильность бедренной кости и не позволяет сместить шейку эндопротеза на достаточное расстояние, за пределы ацетабулярного компонента, снижая визуализацию и доступ к вертлужной впадине. Отсечение же сухожилия средней ягодичной мышцы при переднебоковом подходе позволяет значительно увеличить мобильность бедра, а соответственно, и отвести сохраняемую шейку за заднюю стенку вертлужной впадины. Таким образом, изолированную замену чашки эндопротеза необходимо выполнять из переднебокого доступа к тазобедренному суставу.

\section{Орраничения исследования}

Основным ограничением исследования, способным повлиять на его результаты, является недостаточный срок наблюдения.

В работе представлены среднесрочные результаты наблюдения за пациентами после перенесенного ревизионного вмешательства по поводу асептической нестабильности вертлужного компонента с удалением и без экстракции стабильной правильно ориентированной ножки эндопротеза. За период $22 \pm 7$ мес ни в одном случае признаков расшатывания в сохраненном феморальном компоненте выявлено не было. Однако, учитывая тот факт, что, по данным отчетов национальных регистров, наибольший процент асептической нестабильности отмечается в отдаленном периоде, для достоверности результатов необходимо продление сроков наблюдения до 10-15 лет.
Немаловажным фактором, влияющим на результаты исследования и не поддающимся коррекции со стороны исследователя, является также нарушение пациентами послеоперационного режима, приводящее к развитию осложнений. Как было неоднократно доказано и представлено в литературе, падения в раннем послеоперационном периоде приводят к возникновению ранней асептической нестабильности компонентов эндопротеза, что и наблюдалось в группе с сохранением стабильного правильно ориентированного феморального компонента $(1 / 28 ; 3,6 \%)$ и снизило зарегистрированный процент положительных исходов.

\section{Заключение}

Изолированная замена расшатанной чашки эндопротеза и пары трения является приоритетным методом хирургического лечения асептической нестабильности ацетабулярного компонента. Показанное снижение тяжести ревизионного вмешательства, улучшение послеоперационных результатов и сокращение сроков реабилитации пациентов подтверждает необходимость сохранения стабильного феморального компонента в случае его правильной ориентации. Однако при наличии нестандартного конуса ножки эндопротеза проведение тотального ревизионного вмешательства является вынужденным в связи с отсутствием головок под нестандартные размеры, что, по нашему мнению, требует стандартизации производства или разработки специальных конструкций.

\section{Источник финансирования}

Проведение исследования и подготовка статьи осуществлялись за счет личных средств членов авторского коллектива.

\section{Конфликт интересов}

Авторы данной статьи подтвердили отсутствие конфликта интересов, о котором необходимо сообщить.

\section{Участие авторов}

Концепция и дизайн исследования - Зверева К.П., Марков Д.А.; сбор и обработка материала - Зверева К.П., Трошкин А.Ю.; статистическая обработка - Зверева К.П., Белоногов В.Н.; написание текста - Зверева К.П.; редактирование - Марков Д.А., Сертакова А.В.

\section{ЛИТЕРАТУРА}

1. cihi.ca [Internet]. Hip and Knee Replacements in Canada: Canadian Joint Replacement Registry. 2015 Annual Report [cited 2018 May 29]. Available from: https://www.cihi.ca/en/accessdata-reports/results?query $=$ Hip + and + Knee + Replacements + in + Canada $\% 3 \mathrm{~A}+$ Canadian + Joint + Replacement + Registry. $+\&$ Se $\operatorname{arch}+$ Submit $=$.

2. National Joint Registry for England and Wales. 13th Annual Report. 2016. Available from: http://www.njrreports.org.uk

3. The Swedish Hip Arthroplasty Register. Annual Report 2015. For year 2015. Available from: http://danskhoftealloplastikregister.dk
4. He C, Feng JM, Yang QM, et al. Results of selective hip arthroplasty revision in isolated acetabular failure. J Surg Res. 2010;164(2):228233. doi: $10.1016 /$ j.jss.2009.06.023.

5. Piolanti N, Andreani L, Parchi PD, et al. Clinical and radiological results over the medium term of isolated acetabular revision. ScientificWorldJournal. 2014;2014:148592. doi: 10.1155/2014/148592.

6. de Thomasson E, Conso C, Mazel C. A well-fixed femoral stem facing a failed acetabular component: to exchange or not? A 5- to 15-year follow-up study. Orthop Traumatol Surg Res. 2012;98(1):2429. doi: 10.1016/j.otsr.2011.08.014. 
7. Fukui K, Kaneuji A, Sugimori T, et al. Should the well-fixed, uncemented femoral components be revised during isolated acetabular revision? Arch Orthop Trauma Surg. 2011;131(4):481-485. doi: 10.1007/s00402-010-1152-x.

8. Kalra S, Kumar A, Jarhyan P, Unnikrishnan AG. Endemic or epidemic? Measuring the endemicity index of diabetes. Indian J Endocrinol Metab. 2015;19(1):5-7. doi: 10.4103/2230-8210.144633.

9. Makela KT, Matilainen M, Pulkkinen P, et al. Countrywise results of total hip replacement. An analysis of 438,733 hips based on the Nordic Arthroplasty Register Association database. Acta Orthop. 2014;85(2):107-116. doi: 10.3109/17453674.2014.893498.

10. Gu Q, Shi Q, Yang H. The role of TLR and chemokine in wear particle-induced aseptic loosening. J Biomed Biotechnol. 2012;2012:596870. doi: 10.1155/2012/596870.

11. Waewsawangwong W, Ruchiwit P, Huddleston J, Goodman S. Hip arthroplasty for treatment of advanced osteonecrosis: comprehensive review of implant options, outcomes and complications. Orthop Res Rev. 2016;8:13-29. doi: 10.2147/Orr.S35547.

12. Акулич Ю.В., Подгаец Р.М., Скрябин В.Л., Сотин А.В. Исследование напряженно-деформированного состояния эндопротезированного тазобедренного сустава // Российский журнал биомеханики. - 2007. - Т.11. - №4 - С. 9-35. [Akulich YuV, Podgaets RM, Skryabin VL, Sotin AV. The investigation of stresses and strains in the hip joint after operation of endoprosthetics. Rossiiskii zhurnal biomekhaniki. 2007;11(4):9-35. (In Russ).]

13. Hara K, Kaku N, Tabata T, et al. Isolated acetabular revision for failed bipolar hemiarthroplasty without removal of a wellfixed femoral component. Orthopaedic Proceedings. 2013;95B(15):191.

14. Lawless BM, Healy WL, Sharma S, Iorio R. Outcomes of isolated acetabular revision. Clin Orthop Relat Res. 2010;468(2):472-479. doi: 10.1007/s11999-009-1104-3.

15. Kerboull L. Selecting the surgical approach for revision total hip arthroplasty. Orthop Traumatol Surg Res. 2015;101(1 Suppl):S171-178. doi: 10.1016/j.otsr.2014.07.031.

16. Park YS, Moon YW, Lim BH, et al. A comparative study of the posterolateral and anterolateral approaches for isolated acetabular revision. Arch Orthop Trauma Surg. 2011;131(7):1021-1026. doi: 10.1007/s00402-011-1258-9.

\section{КОНТАКТНАЯ ИНФОРМАЦИЯ}

Марков Дмитрий Александрович [Dmitrii A. Markov, MD, PhD], кандидат медицинских наук, доцент кафедры травматологии и ортопедии ФГБОУ ВО «Саратовский государственный медицинский университет имени В.И. Разумовского» Минздрава России

Адрес: 410012, Саратов, ул. Большая Казачья, д. 112, тел.: +7 (452) 39-31-99, e-mail: m-makar@yandex.ru, SPIN-код: 7459-7910, ORCID: https://orcid.org/0000-0002-1753-248X

Зверева Ксения Павловна [Kseniia P. Zvereva, MD], ассистент кафедры травматологии и ортопедии ФГБОУ ВО «Саратовский государственный медицинский университет имени В.И. Разумовского» Минздрава России Адрес: 410012, Саратов, ул. Большая Казачья, д. 112, тел.: +7 (452) 39-31-99, e-mail: ksenya.zvereva.91@mail.ru, SPIN-код: 5399-6769, ORCID: https://orcid.org/0000-0003-3494-2277

Сертакова Анастасия Владимировна [Anastasiia V. Sertakova, MD, PhD], кандидат медицинских наук, старший научный сотрудник отдела новых технологий в травматологии и ортопедии, врач травматолог-ортопед отдела организационно-методической и научно-образовательной деятельности НИИТОН ФГБОУ ВО «Саратовский государственный медицинский университет имени В.И. Разумовского» Минздрава России

Адрес: 410002, Саратов, ул. Чернышевского, д. 148, тел.: +7 (452) 39-31-99, e-mail: anastasiya-sertakova@yandex.ru, SPIN-код: 8243-8811, ORCID: https://orcid.org/0000-0002-4375-0405

Белоногов Валерий Николаевич [Valerii N. Belonogov, MD, PhD], кандидат медицинских наук, доцент кафедры травматологии и ортопедии ФГБОУ ВО «Саратовский государственный медицинский университет имени В.И. Разумовского» Минздрава России

Адрес: 410012, Саратов, ул. Большая Казачья, д. 112, тел.: +7 (452) 39-31-99, e-mail: belonogov.valerij@list.ru, SPIN-код: 3847-7020, ORCID: https://orcid.org/0000-0003-0896-3525

Tрошкин Александр Юрьевич [Alexander Yu. Troshkin], ординатор кафедры травматологии и ортопедии ФГБОУ ВО «Саратовский государственный медицинский университет имени В.И. Разумовского» Минздрава России Адрес: 410012, Саратов, ул. Большая Казачья, д. 112, тел.: +7 (452) 39-31-99, e-mail: c.t.1993@mail.ru, SPIN-код: 9644-0932, ORCID: https://orcid.org/0000-0003-4078-7111 